\title{
Democratização da educação superior no Brasil: das metas de inclusão ao sucesso acadêmico
}

\section{Resumo}

O artigo aborda aspectos sobre a democratização da educação superior no Brasil, discutindo alguns dos desafios para o cumprimento das metas de inclusão propostas no início do século XXI, em especial as políticas de ação afirmativa adotadas a partir de 2002. Aborda também questões importantes em relação às políticas de permanência na educação superior brasileira, que influenciam nos diferentes percursos em direção ao sucesso acadêmico dos estudantes. O texto parte de pesquisa bibliográfica, da análise de dados secundários e também de resultados de pesquisas realizadas pela autora e por outros integrantes do seu grupo de pesquisa, o LEPES (Laboratório de Estudos e Pesquisas sobre Educação Superior).

Palavras-chave: Ensino superior, realização, Brasil

\section{Abstract: Democratization of higher Education in Brazil: from inclusion targets to academic success}

The paper addresses aspects about the democratization of higher education in Brazil, discussing some of the challenges for the fulfillment of inclusion targets proposed at the beginning of the $21^{\text {st }}$ century, especially affirmative action policies adopted since 2002. It also addresses important issues related to the retention policies in Brazilian higher education, which influence in different ways the direction of students' academic success. The paper starts with a bibliographic research, an analysis of secondary data and the results of researches conducted by the author and other participants from her research group, LEPES (Laboratory of Studies and Research on Higher Education). Keywords: Higher education, achievement, Brazil

\section{Resumen: Democratización de la educación superior en Brasil: de las metas de inclusión al éxito académico}

El artículo aborda aspectos sobre la democratización de la educación superior en Brasil, debatiendo algunos desafíos para el cumplimento de las metas de inclusión propuestas al inicio del siglo XXI, en especial las políticas de acción afirmativa adoptadas a partir del 2002. También se abordan cuestiones importantes con relación a las políticas de permanencia en la educación superior brasileña y su influencia en las diferentes trayectorias para el éxito académico de los estudiantes. El texto parte de una investigación bibliográfica, análisis de datos secundarios y de resultados de estudios realizados por la autora y por otros integrantes del grupo científico Laboratorio de Estudios e Investigaciones sobre Educación Superior (LEPES).

Palabras clave: Educación superior, logro, Brasil

\footnotetext{
${ }^{1}$ E-mail: rosana.heringer@gmail.com
} 
A proposta deste artigo é abordar aspectos relativos à democratização da educação superior no Brasil ao longo das últimas décadas. Nesta perspectiva, discutiremos em particular as políticas de ação afirmativa no acesso às instituições de ensino superior públicas, que tiveram início a partir de 2002. Abordaremos também alguns desafios que se apresentam em relação às políticas de permanência na educação superior brasileira, que influenciam nos diferentes percursos em direção ao sucesso acadêmico dos estudantes.

Ao longo do século XX experimentamos uma grande expansão da educação superior em termos mundiais. Estudos apontam um aumento de 500 mil para $100 \mathrm{mi}-$ lhões de estudantes matriculados no ensino superior em nível mundial, entre 1900 e 2000 (Neves, Sampaio, \& Heringer, 2018). Numa perspectiva mais recente, observamos que, entre 1995 e 2011, houve um aumento de 82 milhões para 185 milhões de estudantes frequentando o ensino superior no mundo (Prates \& Collares, 2014).

Vários estudos apontam que a educação superior continua sendo um fator significativo de mobilidade social ascendente nas sociedades contemporâneas (Menezes Filho \& Oliveira, 2014). Sabe-se também que o acesso à educação superior permite uma ampliação não apenas de conhecimentos ligados à formação profissional, mas também em termos de expansão de visões de mundo e acesso a informação (Baker, 2014).

No caso brasileiro, houve uma expressiva expansão de matrículas na educação superior ao longo dos últimos anos. Entre 2003 e 2017, por exemplo, as matrículas na educação superior passaram de 4 milhões para 8,3 milhões (INEP/MEC, 2018), sendo 75\% em instituições privadas. Ainda que tenha obtido expressivos avanços, o país não conseguiu atingir as metas de expansão previstas no Plano Nacional de Educação de 2001, que trazia o plano de 30\% de jovens de 18 a 24 anos matriculados na educação superior em 2011 (Nunes et alli, 2003) e chegamos a 2017 com apenas $19,7 \%$ dos jovens nesta faixa etária frequentando o ensino superior (INEP/MEC, 2018).

Apesar do não alcance das metas, a expansão do ensino superior brasileiro possibilitou a inserção neste nível de ensino de estudantes pertencentes a grupos antes pouco presentes na educação superior. Esta diversificação de públicos e perfis de estudantes ocorreu de forma significativa nas instituições federais de educação superior (IFES), que tiveram uma expansão de matrículas de 600 mil em 2003 para 1,3 milhão em 2017 (INEP/MEC, 2018).

Sabemos da seletividade destas instituições e das dificuldades que ainda hoje alunos que cursaram a educação básica em escolas públicas enfrentam para acessá-las. Mesmo com estas dificuldades, foi expressiva a transformação ocorrida nos campi das IFES brasileiras, que possibilitaram uma diversificação de perfis estudantis e representam um passo importante na democratização do acesso ao ensino superior brasileiro (Ristoff, 2013).

Tal diversificação trouxe também desafios e inquietações para as IFES que recebem estes estudantes, colocando de forma incontornável a dimensão necessária da discussão sobre as políticas de permanência estudantil e sobre que aspectos podem favorecer de maneira efetiva a afiliação destes estudantes à vida universitária (Coulon, 2008), ampliando as perspectivas de seu sucesso acadêmico. Estas serão algumas dimensões tratadas no presente texto.

Além desta introdução, o artigo está organizado em três partes. A primeira abordará as principais políticas de acesso ao ensino superior desenvolvidas no Brasil ao longo das últimas décadas, com especial atenção às políticas de ação afirmativa. Em seguida discutiremos os principais desafios relacionados à permanência dos estudantes no ensino superior. Seguem-se então as considerações finais, abordando os principais pontos discutidos e apresentando algumas questões futuras de pesquisa.

\section{Breve histórico da expansão do ensino superior no Brasil e o papel das políticas de inclusão}

O universo das instituições de ensino superior no Brasil (IES) pode ser resumidamente descrito da seguinte forma: de acordo com o Censo da Educação Superior existiam em 2017 no Brasil 2.448 IES, sendo 199 universidades, 189 centros universitários e 2020 faculdades, sendo estas em sua quase totalidade privadas (INEP/MEC, 2018).

As preocupações sobre a inclusão na educação superior no período recente têm como ponto de partida a percepção da grande distância entre o Brasil e demais países com situação econômica similar quando se trata de acesso à educação superior. O Brasil se posiciona atrás da maioria dos países de renda média e fica atrás também quando comparado com a maioria dos países latino-americanos (Neves, 2012). As raízes desta baixa frequência na educação superior têm diferentes tipos de causa. A primeira delas refere-se à gigantesca desigualdade de oportunidades no país. O sistema de educação básica brasileiro possui tanto escolas públicas quanto privadas, sendo estas últimas em menor número, em geral de melhor qualidade e acessíveis àqueles que podem pagar. O sistema educacional privado na educação básica é ocupado principalmente por estudantes de classe média e alta, que podem custear altas mensalidades. Estudantes que concluem o ensino básico nestas escolas são tradicionalmente aprovados em maior proporção nos exames para ingresso nas 
melhores universidades brasileiras que, ironicamente, são em sua maioria públicas e sem custos para o estudante. As consequências desta estrutura no longo prazo são a grande concentração de estudantes de maior renda e brancos nas universidades públicas.

Os estudantes de menor renda, em sua maioria pretos e pardos, que em geral frequentaram escolas públicas de menor qualidade na educação básica, não têm muitas opções a não ser tentar ingressar em instituições de educação superior privadas, pelas quais tem que pagar. Estas instituições em sua maioria são de menor qualidade se comparadas com as públicas, e oferecem, na maioria dos casos, diplomas de menor prestígio no mercado de trabalho.

Assim se apresenta o quadro referente ao ingresso na educação superior no Brasil nas últimas décadas. $\mathrm{O}$ sistema de educação superior no Brasil foi, desde sua criação e durante muitos anos, pequeno e exclusivo, pensado para atender uma pequena elite (Almeida, 2012). A primeira onda de expansão do número de matrículas ocorreu nos anos de 1960, como resultado de grande pressão de uma classe média emergente que almejava alcançar a educação superior. Entretanto esta expansão aconteceu principalmente através do crescimento do setor privado, com incentivos por parte do estado, através de isenções fiscais, realizando uma expansão rápida para suprir a demanda crescente. Ainda assim a questão do acesso limitado à educação superior permaneceu, já que estes cursos eram pagos e muitas pessoas que tinham a expectativa de ingressar na educação superior não tinham como custear seus estudos, ou o faziam com grande dificuldade.

Nas décadas seguintes, entre 1970 e 2000, houve basicamente a manutenção deste mesmo modelo: o crescimento do setor privado, com cerca de $70 \%$ das matrículas e um número insuficiente de vagas nas instituições públicas que não se expandiram muito no ensino de graduação neste período. Foi apenas a partir dos anos 1990 e início dos anos 2000 que a percepção sobre o caráter injusto do acesso à educação superior no Brasil foi percebida e diferentes forças sociais se mobilizaram por mudanças. Neste período, em função da expansão da educação básica e do maior número de matrículas no ensino médio, houve um maior "estoque" de jovens concluintes do ensino médio que poderiam potencialmente ingressar na educação superior.

Um dos principais movimentos sociais que emergiram neste período, tendo grande importância no esforço pela democratização do acesso à educação superior foi o chamada PVNC - Pré-Vestibular para Negros e Carentes. O PVNC se iniciou como um movimento social na periferia do Rio de Janeiro que, com o apoio da igreja católica, reuniu um número significativo de estudantes e professores voluntários na organização de cursos gratuitos para estudantes pobres e negros se prepararem para os exames de ingresso na educação superior (Santos, 2003).

A mobilização deste e de outros movimentos sociais e atores políticos pela democratização do acesso a educação superior pública produziu resultados importantes. A partir dos anos 2000, o governo brasileiro deu início a algumas políticas para ampliar o número de estudantes no ensino superior. As políticas envolveram diferentes medidas, tais como:

- Expansão do sistema universitário público, com a criação de 18 universidades federais entre 2003 e 2014);

- Expansão das universidades federais já existentes, incluindo novos prédios, novos cursos e novos campi

- Criação em 2004 do ProUni, programa de bolsas do governo federal para estudantes em instituições privadas, com a concessão de 1,2 milhões de bolsas entre 2004 e 2010 (Santos, 2011)

- Ampliação do FIES (Financiamento estudantil)

- Expansão e criação de institutos federais de educação técnica e tecnológica

- Políticas de ação afirmativa, beneficiando diferentes públicos.

A combinação destas diferentes políticas resultou num crescimento significativo do sistema de ensino superior como um todo. Se a maioria destas políticas incidiram diretamente na expansão de vagas e na ampliação do alcance, territorial inclusive, das IFES, do ponto de vista da inclusão e da diversificação dos públicos que passam a acessar a educação superior, as políticas de ação afirmativa têm tido um papel significativo. Por esta razão abordaremos a seguir os aspectos mais significativos referentes à implantação das políticas de ação afirmativa no Brasil (Heringer, Sampaio, Santos, 2016).

\section{A experiência brasileira de políticas de ação afirmativa no acesso ao ensino superior}

O debate sobre ação afirmativa no Brasil é relativamente recente, datando de meados dos anos 1990. De uma maneira geral, o movimento negro brasileiro tem sido o responsável pela introdução deste tema no debate público do país. Inicialmente (e ainda em parte) o assunto é alvo de muitas críticas e resistências à sua incorporação. As críticas mais comuns destacam que políticas específicas trariam conflito e divisionismo a um país onde as relações raciais seriam harmônicas. As críticas relacionam-se também à inadequação de políticas deste tipo, uma vez que a situação desvantajosa da população negra estaria associada ao seu baixo grau de escolaridade. Portanto, uma 
melhoria geral das políticas educacionais traria os benefícios esperados à população afro-brasileira.

As informações e análises aqui apresentadas resultam de vários anos de pesquisa sobre as políticas de ação afirmativa no Brasil que temos desenvolvido ao longo das duas últimas décadas. Tais pesquisas abordaram tanto os debates iniciais sobre desigualdades raciais no Brasil que embasaram estas políticas (Heringer, 2001, 2002a; 2002b) quanto aspectos normativos relativos a implementação das mesmas (ver por exemplo Heringer $\&$ Ferreira, 2009). Também nos dedicamos na última década à análise sobre a institucionalidade das políticas de ação afirmativa (Heringer, 2010; 2012) e aos desafios colocados a partir de sua implementação (Heringer, 2013a; Heringer, 2013b).

Afirmamos que falar das ações afirmativas no Brasil significa falar de uma experiência de sucesso. Significa analisar uma política que foi criada a partir da pressão de setores da sociedade tradicionalmente discriminados e que, uma vez iniciada sua implementação, vem se ampliando e consolidando ano após ano. Por outro lado, é importante destacar que o processo político que levou à criação destas políticas não foi um caminho sereno e sem conflitos. Ao contrário, trata-se de um caminho cheio de percalços, permeado por disputas entre diferentes atores envolvidos e também por construção de consensos à custa de muita negociação (Heringer \& Johnson, 2015).

Aqueles que estiveram de alguma forma envolvidos no processo preparatório da Conferência Mundial contra o Racismo, em Durban, África do Sul, realizada em 2001, certamente se lembram dos intensos debates que subsidiaram a construção do documento brasileiro levado à conferência, bem como as dezenas de eventos que aconteceram em todo o país visando ampliar a visibilidade deste debate e também ampliar as adesões de diferentes setores da sociedade brasileira, para além do movimento negro e antirracista e do movimento indígena, à causa das ações afirmativas.

Outra característica importante deste momento no início dos anos 2000 foi a ampliação da disponibilidade de dados e indicadores sociais que revelavam a dimensão das desigualdades raciais no Brasil, em muitos aspectos sociais e econômicos. Estudos significativos possibilitaram à sociedade brasileira conhecer melhor o tamanho das desigualdades, ampliando portanto, a possibilidade de pensar alternativas de políticas visando a redução das mesmas e a ampliação de oportunidades (Paixão et alli, 2011).

Tendo como marco a adoção da política de reserva de vagas para estudantes de escola pública, pretos e pardos adotada pela primeira vez pela UERJ (Universidade do Estado do Rio de Janeiro) e pela UNEB (Universidade Estadual da Bahia), analisaremos a seguir os principais avanços e desafios que identificamos na implementação das políticas de ação afirmativa no Brasil a partir de 2002.

O primeiro aspecto que consideramos positivo ao fazer o balanço das políticas de ação afirmativa na educação superior na última década refere-se à ampliação do acesso de estudantes de escola pública, pretos, pardos e indígenas ao ensino superior. Os dados apresentados na Tabela 1 demonstram que houve ampliação expressiva do acesso ao ensino superior por parte de estudantes pretos e pardos ao longo da década.

Tabela 1

Taxa líquida de matrículas por raça/cor, Brasil, 2001-2014

\begin{tabular}{lccccccccccccc}
\hline & 2001 & 2002 & 2003 & 2004 & 2005 & 2006 & 2007 & 2008 & 2009 & 2011 & 2012 & 2013 & 2014 \\
\hline Brancos & 14,5 & 15,8 & 17,2 & 16,5 & 17,6 & 19,7 & 20,2 & 20,8 & 21,6 & 21,3 & 22,4 & 23,6 & 25,3 \\
Pretos & 2,2 & 3,2 & 4,3 & 4,8 & 6,3 & 6,5 & 6,4 & 7,5 & 7,5 & 7,9 & 8,2 & 10,2 & 11,4 \\
Pardos & 3,6 & 4,0 & 4,7 & 5,2 & 5,7 & 6,5 & 7,2 & 7,9 & 8,8 & 9,7 & 10,3 & 11,2 & 12,1 \\
\hline
\end{tabular}

Fonte: IBGE/Pnad - Elaboração: Todos Pela Educação

Apesar dos avanços expressivos no acesso de pretos e pardos ao ensino superior, se comparamos este dado com o aumento da frequência de estudantes brancos nesta faixa de ensino observamos que a defasagem entre brancos e pretos/pardos continua grande. A presença de estudantes brancos de 18 a 24 anos no ensino superior saltou de $14,5 \%$ em 2001 para $25,3 \%$ em 2014 e se mantém, portanto, bastante acima da proporção de estudantes pretos e pardos neste nível de ensino.

Estes indicadores demonstram que o avanço, apesar de expressivo, ainda precisa ser ampliado nos próximos anos. Podemos afirmar que estamos avançando na direção certa, porém em uma velocidade ainda insuficiente para dar conta das grandes 
defasagens existentes entre os grupos de cor no acesso ao ensino superior.

As políticas de ação afirmativa adotadas ao longo da década por instituições federais e estaduais de educação superior também contribuíram para esta ampliação do acesso. Após a adoção da reserva de vagas para estudantes de escola pública, pretos e pardos pela UERJ e pela UNEB em 2001/2002, houve um aumento progressivo do número de instituições que adotou reservas de vagas semelhantes ao longo da década seguinte, chegando-se ao número de 115 instituições públicas de educação superior com algum tipo de reserva de vagas em 2012 (Jodas \& Kawagami, 2011).

Outro aspecto que destacamos como avanço no campo das políticas de ação afirmativa foi justamente a maior legitimidade alcançada pelas mesmas ao longo da última década. Em 2010 publicamos um artigo analisando justamente as potencialidades e limites da institucionalidade até então alcançada pelas políticas de ação afirmativa na educação superior (Heringer, 2010), destacando a preocupação de que a forma como as políticas vinham sendo adotadas nas universidades deixava margem para dúvidas sobre sua continuidade ao longo do tempo, já que as decisões se baseavam principalmente em normas aprovadas pelos conselhos universitários ou órgãos superiores equivalentes nas universidades e ficariam portanto mais sujeitos a mudanças conjunturais de ordem política dentro de cada instituição.

As instituições que começaram a implantar programas de ação afirmativa na primeira metade da década de 2000 têm apresentado periodicamente resultados de avaliações institucionais que apontam os efeitos dessas políticas na distribuição de oportunidades educacionais no ensino superior e nos trazem importantes indicadores sobre o papel estratégico desses programas ao possibilitar a formação de novos profissionais que chegam ao mercado de trabalho como a primeira geração beneficiada pela ação afirmativa. Saber como o mercado de trabalho vai recebê-los é uma tarefa importante para compreender o alcance dessas políticas.

O ano de 2012 representou um marco importante no cenário destas políticas. No primeiro semestre o Supremo Tribunal Federal reconheceu por unanimidade a constitucionalidade das políticas de ação afirmativa, inclusive utilizando o recorte racial. Em agosto, foi promulgada a Lei 12.711/12, que determina a adoção de reservas de vagas nas instituições federais para estudantes de escola pública, estudantes de menor renda, pretos, pardos e indígenas. Com este novo cenário, é ainda mais importante olhar para as experiências em curso, buscando avaliá-las e identificar elementos que possam contribuir para seu aperfeiçoamento. Sem dúvida o tema das políticas de permanência está no centro destas reflexões.

Poucos meses após a votação favorável e significativa no STF, foi a vez do Congresso brasileiro dar um passo decisivo com a aprovação da Lei 12.711, que instituiu cotas nas instituições federais de ensino. Tal lei foi resultante de um projeto de lei que tramitou por mais de uma década no Congresso. A lei estipula que até 2016 pelo menos 50\% das vagas das instituições federais de educação superior fossem reservadas para estudantes de escola pública. Dentro deste percentual, também são levados em conta a renda familiar e a autoclassificação racial, definindo um percentual de cotas para pretos, pardos e indígenas de acordo com a sua presença em cada unidade da federação, seguindo os dados do IBGE. Levantamento realizado pelo GEMAA revela que, neste curto espaço de tempo de implementação da lei, já se pode observar um crescimento de $225 \%$ no número de vagas reservadas para estudantes pretos, pardos e indígenas (Daflon et alli, 2014).

A Lei n. ${ }^{\circ} 12.711$, de 29 de agosto de 2012 (Lei das Cotas), estabelece que as IFES vinculadas ao MEC reservarão, em cada concurso seletivo para ingresso nos cursos de graduação, por curso e turno, no mínimo $50 \%$ de suas vagas para estudantes que tenham cursado integralmente $o$ ensino médio em escolas públicas. Esse total é subdividido entre estudantes de escolas públicas com renda familiar igual ou inferior a um salário mínimo e meio per capita (25\%) e estudantes de escolas públicas com renda familiar superior a um salário mínimo e meio, ou seja, as demais rendas (25\%). Em ambos os casos, é levado em conta o percentual mínimo correspondente ao da soma de pretos, pardos e indígenas no estado, de acordo com o último censo demográfico do IBGE (2010). O diagrama a seguir ilustra os critérios para implementação da lei 12.711/2012.

A partir da implementação da Lei de Cotas, o candidato que realizou o ENEM pode, por intermédio do SISU, concorrer a uma vaga nas IFES, em uma das cinco modalidades, a saber: I- Ampla concorrência (AC); II- Egresso de escola pública (EP); III- Egresso de escola pública e baixa renda (EP+BR); IV- Egresso de escola pública e autodeclarado preto, pardo ou indígena (EP+PPI); V- Egresso de escola pública, autodeclarado preto, pardo ou indígena e baixa renda (EP+PPI+BR). Os estudantes que desejarem se beneficiar das cotas nas modalidades apontadas acima (exceto a ampla concorrência) devem comprovar que estudaram todo o ensino médio em escola pública (Martins, 2018). A partir de 2016 agregou-se também a esta política de reserva de vagas a cota para pessoas com deficiência (Lei $\mathrm{n}^{\mathrm{o}} 13.049 / 2016$ ), que passou a ser implementada a partir da seleção através do ENEM/SISU para ingresso em 2017 Heringer \& Klitzke, 2017). 


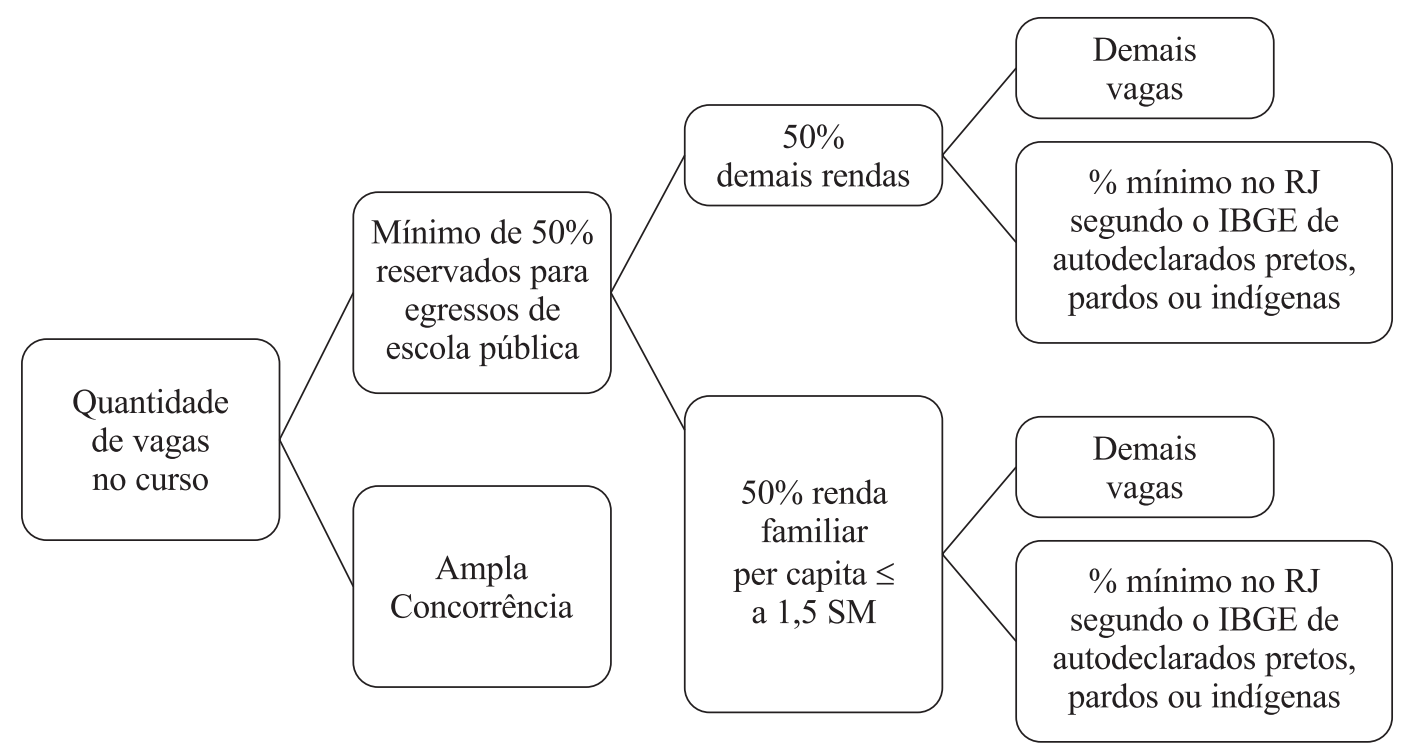

Figura 1. Modalidades de ação afirmativa definidas pela Lei 12.711/2012

Fonte: Martins, Melina Klitzke, 2018. Há tendência de democratização do acesso a cursos de prestígio na UFRJ? Análise com base no perfil dos ingressantes - 2013-2016. Dissertação (Mestrado em Educação), UFRJ.

Estas mudanças legais e institucionais recentes trazem uma dimensão importante de legitimidade do tema e das políticas de ação afirmativa para o conjunto da sociedade brasileira, levando a redução de resistências em relação a estas políticas seja dentro das instituições de ensino superior ou no âmbito da opinião pública. Embora ainda vejamos manifestações críticas às políticas de ação afirmativa em jornais de grande circulação, tais declarações não parecem ter um grande peso e repercussão junto à opinião pública.

De forma geral, há uma avaliação positiva da implementação destes programas, porém outros desafios se apresentam ao avanço das políticas de democratização do ensino superior. Tais desafios se concentram hoje em relação às políticas de permanência para os estudantes universitários. Uma vez admitidos às instituições de educação superior, como fazer para que um amplo contingente de estudantes tenha condições de permanecer, ter sucesso e concluir seu curso superior?

\section{Os desafios da permanência estudantil: múltiplos percursos para o sucesso acadêmico}

Consideramos que o sucesso efetivo das políticas de inclusão na educação superior vai se dar plenamente na medida em que sejam garantidas as condições de igualdade de oportunidades para os estudantes de diferentes origens sociais e características socioeconômicas na sua vivência, integração, percepção, apropriação e afiliação ao ambiente universitário. Tais condições, a nosso ver, são geradas por um conjunto de medidas de ordem institucional e também por disposições dos atores envolvidos, principalmente gestores, docentes, funcionários e colegas que possibilitem a efetiva inserção destes estudantes na vida universitária.

Para melhor compreender as dificuldades enfrentadas pelos estudantes com origem social menos privilegiada e de grupos tradicionalmente excluídos do ensino superior, podemos lançar mão de reflexões empreendidas por Pierre Bourdieu, como representante das formulações já clássicas da sociologia das desigualdades de oportunidades educacionais, e também de Alain Coulon. Ao descrever o processo de aumento do acesso ao ensino secundário por parte de grupos "culturalmente desfavorecidos" na França, Bourdieu apontou um processo semelhante ao que pode estar ocorrendo hoje no Brasil em relação ao ensino superior. Após um período de ilusão e euforia, os novos beneficiários do secundário teriam compreendido, pouco a pouco, que não bastava ter acesso a este nível de ensino para ter êxito nele. Bourdieu apontou o risco de as promessas de democratização feitas não se concretizarem e de que muitos jovens vejam seus planos serem logrados.

Bourdieu \& Champagne (1992) apontam que, ao contrário dos alunos "bem nascidos", que recebem de suas famílias todas as condições e recursos de realizar seus investimentos na trajetória escolar (e social), os alunos que viriam de famílias mais desprovidas seriam obrigados a submeter-se às injunções das instituições escolares ou ao 
acaso para encontrar seu caminho num universo cada vez mais complexo. Desse modo, poderíamos refletir sobre a importância das políticas de permanência. Estudantes menos privilegiados não podem contar com a família (ou contam de forma reduzida) para os apoiarem nas demandas surgidas em função de uma escolarização prolongada. Assim, acabam tendo que criar suas próprias práticas e estratégias ou contar com eventuais mecanismos institucionais de apoio à sua permanência no ambiente universitário e/ou para assisti-los na oferta de algum recurso.

Alain Coulon (2008), em suas reflexões sobre a "condição de estudante", analisou o processo de adaptação e integração à vida universitária por parte de estudantes franceses (da Universidade de Paris 8), chegando a criar uma tipologia para abordar o que definiu como "processo de afiliação". Assim, demonstrou que este processo - por meio do qual o aluno passa à "condição de estudante" - se dá de forma gradual e é atravessado por distintas etapas, e o estudante passaria a ter um novo status social, quando se integra plenamente a esse novo contexto cultural (a universidade). Esta integração, envolvendo a apreensão de códigos, rotinas, ações e comportamentos, seria fundamental numa trajetória escolar de sucesso, e, com efeito, posteriormente, por que não, para a inserção no mundo do trabalho. As diferentes etapas, chamadas por Coulon (2008) de "tempos", seriam as "da entrada" na universidade, "do estranhamento" e "da aprendizagem"; em conjunto significariam um "aprendizado do ser estudante" de ensino superior. Entre as atividades descritas para estas distintas etapas o autor aponta o domínio na organização do próprio tempo, de modo a dar conta de várias tarefas; 0 domínio da localização e conhecimento dos serviços disponíveis pela instituição de ensino; o desenvolvimento de uma rede de suporte afetivo; a participação em atividades de integração, entre outras. Desse modo, seria importante compreendermos se as políticas de permanência e assistência estudantil estão funcionando de forma a suscitar esse processo de afiliação - institucional e/ou intelectual - ou não. A distribuição de bolsas sociais, por exemplo, deveria estar associada a projetos mais amplos de vivência acadêmica. De acordo com Coulon, a afiliação institucional seria bem sucedida quando "o estudante consegue interpretar, usar e jogar com as regras da instituição, descobrir aquelas que estão escondidas e utilizá-las na construção individualizada de seu percurso" (Coulon, 2008).

Estas diferentes gradações no processo de apropriação pelo estudante em relação ao espaço universitário podem ser utilizadas como um referencial relevante para observarmos a inserção deste novo grupo de estudantes que têm ingressado no ensino superior no Brasil ao longo da última década. Este processo guarda suas especificidades de acordo com o tipo de instituição em que o estudante ingressa; com características de sua origem familiar; com o suporte institucional que o estudante venha a receber para permanecer no ensino superior (Heringer \& Honorato, 2014; Honorato \& Heringer, 2015).

As experiências de ação afirmativa, juntamente com a expansão do sistema durante os anos 2000 promoveram maior inclusão, porém ainda há muitos obstáculos a serem ultrapassados. Os problemas se concentram nas dificuldades enfrentadas pelos estudantes de menor renda para permanecer na universidade, principalmente do ponto de vista das dificuldades financeiras. As políticas de assistência estudantil ainda engatinham na sociedade brasileira e, mesmo quando existem, estas políticas não necessariamente alcançam todos os estudantes que as solicitam (Vargas, 2012; Sousa \& Portes, 2011).

Podemos dizer que há um desafio para as instituições de ensino superior públicas, especialmente as de maior prestígio, para considerar efetivamente como parte de suas tarefas e responsabilidades a necessidade de lidar com a emergência deste novo perfil de estudante universitário, que chega com diferentes necessidades e requer atenção especial por parte das instituições. É importante destacar que muitos destes estudantes pertencem à primeira geração das suas famílias a ingressar no ensino superior. Vários estudantes que conseguiram ingressar numa universidade pública nos anos recentes experimentam dificuldades em termos econômicos e também em termos do acesso a diferentes oportunidades de inclusão em atividades oferecidas pelas universidades.

Interessa-nos refletir sobre questões cruciais suscitadas pelo desenho e implementação das políticas de assistência estudantil nas universidades federais. Essa questão nos remete a outra de cunho mais teórico, sobre o fundamento da assistência estudantil como direito. Definimos o que entendemos por "permanência" e por "assistência estudantil". As políticas de permanência possuiriam maior abrangência, incluindo aspectos relacionados a diferentes formas de inserção plena na universidade, como por exemplo, programas de iniciação científica e à docência, apoio à participação em eventos, entre outras atividades. As políticas de assistência estudantil estariam contidas nas políticas de permanência, mas teriam um foco mais específico nas ações necessárias para viabilizar a frequência às aulas e demais atividades acadêmicas. Concordamos com Menezes (2012, p. 73) em sua definição de políticas de assistência, que pode ser traduzida como um mecanismo de direito social: que transita por diversas áreas, compreendendo ações que vão desde o acompanhamento das necessidades especiais dos estudantes até o provimento de recursos mínimos (moradia, alimentação, transporte, 
recursos financeiros) para o alcance dos objetivos de permanência na educação superior. É composta por ações universais e/ou focalizadas em determinados segmentos com necessidades específicas. Tais ações buscam apoiar a permanência dos estudantes na universidade para que possam concluir sua graduação com bom aproveitamento acadêmico. As políticas de permanência devem ser pensadas para todo e qualquer estudante universitário, enquanto as políticas de assistência se destinam àqueles em situação de vulnerabilidade, vivenciando circunstâncias que possam comprometer sua permanência, incluídas aí as dificuldades de ordem financeira. Entretanto, na prática e nos diferentes arranjos institucionais para a implementação dessas políticas, as ações de permanência e assistência estudantil estão integradas, superpostas ou mesmo confundidas (Honorato, Heringer, Vargas, 2014).

Como uma das maneiras de responder a estes desafios, o governo brasileiro criou em 2010 o PNAES - Programa Nacional de Assistência Estudantil - com os seguintes objetivos: "1. democratizar as condições de permanência dos jovens na educação superior pública federal; 2. minimizar os efeitos das desigualdades sociais e regionais na permanência e conclusão da educação superior; 3 . reduzir as taxas de retenção e evasão; e 4. contribuir para a promoção da inclusão social pela educação" (BRASIL, 2010).

Com o propósito de concretizar estes objetivos, o PNAES definiu ações que deverão ser adotadas nas seguintes áreas: moradia; alimentação; transporte; atenção à saúde; inclusão digital; cultura; esportes; educação infantil para filhos de estudantes; acesso, participação e aprendizagem de estudantes portadores de deficiência (BRASIL, 2010).

Embora os recursos destinados ao PNAES tenham se ampliado significativamente entre 2008 e 2013, chegando a 650 milhões naquele ano, com o pagamento de 1.415.185 auxílios (em comparação com $198.000 \mathrm{em}$ 2008), tal expansão se revelou insuficiente para garantir o apoio necessário para atender à crescente demanda por assistência estudantil no período. Tal situação agravou-se ainda mais nos anos após 2015, com a crise econômica e fiscal que atingiu o país, provocando expressiva redução de gastos públicos.

Como forma de melhor conhecer as políticas de assistência em curso nas IFES, realizamos, em conjunto com a Profa. Hustana Vargas, um estudo exploratório sobre as políticas de assistência estudantil oferecidas pelas 63 IFES então existentes em 2015. Foi realizada uma análise das características e abrangência das políticas de permanência e assistência estudantil que vêm sendo desenvolvidas pelas universidades federais brasileiras na última década e, especialmente, após 2012, com a implementação da
Lei 12.711, Lei de Cotas e a ampliação dos recursos do PNAES (Plano Nacional de Assistência Estudantil).

A análise baseou-se no levantamento feito nos websites de todas as 63 universidades federais à época (sempre que a informação estava disponível), observando o setor responsável pela política de assistência estudantil (PróReitoria ou outro); os tipos de auxílios e bolsas concedidos, o valor das bolsas ofertadas e os critérios para concessão e renovação destes auxílios (Vargas \& Heringer, 2016).

Nesse trabalho mostramos em primeiro lugar a urgência da atenção ao tema, em virtude das características sócio históricas do ensino superior no Brasil e das recentes políticas públicas de expansão que visam também alterar sua frequência, direcionando ações para a diminuição de desigualdades sociais de várias ordens. Especificamente, destacamos o Programa de apoio a Planos de Reestruturação e Expansão das Universidades Federais (REUNI) em 2007 como divisor de águas neste processo.

Após consulta aos websites das universidades federais, levantamos informações sobre os tipos de benefícios oferecidos pelas mesmas. Para fins de análise, classificamos os benefícios em cinco grandes grupos, como vemos a seguir:

1. Bolsa auxílio ou permanência;

2. Moradia (oferta de vagas em residência estudantil ou auxílio moradia);

3. Alimentação (inclui tanto a oferta de restaurante universitário, com gratuidade ou refeição subsidiada quanto auxílio financeiro destinado á alimentação);

4. Transporte (inclui auxílio financeiro destinado a transporte, bem como créditos, vale-transporte ou similar no transporte local municipal ou intermunicipal);

5. Outros benefícios: aqui foram agrupados todos os benefícios que não se enquadravam nas opções anteriores. Reúne ampla gama de benefícios, que será detalhada posteriormente.

Em um grande número de instituições, as transferências monetárias são frequentemente associadas ao objetivo de suprir um determinado benefício, qual seja, alimentação, transporte ou moradia. Em muitos casos, embora o termo utilizado seja "bolsa", trata-se de um auxílio específico destinado a um destes fins (ou uma combinação deles).

$\mathrm{Na}$ categoria "outros benefícios" agrupamos todas as modalidades de apoio aos estudantes, constantes ou não das ações listadas no PNAES, que foram identificadas nos websites das universidades federais e não se referem aos benefícios descritos anteriormente. Houve uma grande variedade de tipos de benefícios listados nesta categoria, que envolvem tanto apoios eventuais, emergenciais e temporários, quanto outros que podem se estender ao longo de todo o curso e visam melhorar as condições de vida dos estudantes. 
Nossa percepção ao analisar estes dados é de que as universidades capazes de combinar em suas políticas de assistência estudantil tanto o apoio material voltado para as necessidades básicas quanto as atividades de apoio pedagógico e de ampliação de oportunidades acadêmicas para os estudantes serão aquelas melhor sucedidas na garantia da permanência e sucesso acadêmico de seus alunos (Vargas \& Heringer, 2017).

Esta abordagem leva a uma nova maneira de tratar tais políticas, influenciando sua concepção, desenho, definição dos beneficiários e elegibilidade; também implica numa diversificação dos serviços e tipos de apoio oferecidos aos estudantes; implica, principalmente, numa concepção de assistência estudantil que vai além do apoio financeiro e tenta abordar diferentes aspectos que são pré-condições para que os estudantes desenvolvam todas as suas capacidades a partir do momento que se matriculam numa instituição federal de educação superior.

Esta abordagem traz a necessidade de que as instituições estejam muito mais comprometidas com o sucesso de todos os estudantes, nos mais variados aspectos; de que as mesmas tenham mais profissionais treinados e preparados para lidar com as novas situações que surgem. Uma das implicações desta nova interpretação é o desenvolvimento de uma percepção distinta sobre quem é este novo estudante e quais são suas dificuldades para se engajar plenamente nos estudos. Também é importante que o corpo docente e demais servidores das IFES estejam aptos a olhar para estes novos estudantes sem preconceitos do ponto de vista socioeconômico, étnico ou racial e com disposição para acolher suas contribuições para o conjunto deles. A fim de que esta postura se concretize, é necessário que docentes e técnicos sejam sensibilizados em relação a estes aspectos.

\section{Considerações finais}

Em 2001, o IBGE divulgou dados sobre o acesso ao ensino superior no Brasil, mostrando que apenas $2,2 \%$ dos jovens pretos e 3,6\% dos jovens pardos frequentavam universidades e faculdades. Estes dados confirmavam uma informação que já era conhecida pela sociedade brasileira, principalmente por aqueles que frequentavam o ambiente universitário: o sistema de ensino superior no país era majoritariamente branco, elitizado, com a maior parte dos seus estudantes vindo de escolas particulares.

Tanto sob o aspecto da justiça e equidade social quanto do ponto de vista do desenvolvimento científico e tecnológico do país, estes dados eram inaceitáveis. Naquele momento muitos ativistas do movimento negro trouxeram com ainda mais força a bandeira da democratização do acesso à educação superior no país, principalmente às universidades públicas federais, conhecidas pela sua qualidade e seletividade.

As políticas de ação afirmativa adotadas a partir de 2002 , juntamente com outras ações e programas voltados para a expansão do ensino superior brasileiro, tanto público como privado, provocaram mudanças significativas no perfil dos estudantes universitários, principalmente nas instituições mais seletivas.

Embora tenham se consolidado do ponto de vista institucional e as resistências às mesmas tenham diminuído, é possível observar que o debate sobre as políticas de democratização do ensino superior e sobre as ações afirmativas em particular é amplo e virtualmente impossível de concluir. Destacamos que é importante acompanhar os efeitos e resultados destas políticas e esperamos que um dia as mesmas não sejam mais necessárias, pois todos terão as mesmas oportunidades de escolha.

Diante dos desafios aqui apresentados, é muito importante que a sociedade brasileira continue debatendo as políticas de ação afirmativa, e que os resultados das medidas que vêm sendo implementadas possam ser conhecidos e compreendidos pelo conjunto da população e, principalmente por aqueles que potencialmente poderão ser beneficiados por tais medidas.

Em relação às políticas de permanência na educação superior, as informações e reflexões aqui apresentadas apontam para uma importância crescente destas políticas como um componente significativo do sucesso acadêmico dos estudantes. A permanência material, expressa em bolsas e outros auxílios financeiros, é uma medida importante, porém, insuficiente para garantir a trajetória bem sucedida de muitos estudantes. Crescentemente temos observado que ações como apoio acadêmico ganham importância crescente na permanência estudantil, e tem recebido cada vez atenção das IFES. Em muitos casos, observamos que as ações de permanência não se traduzem necessariamente num grande volume de recursos envolvidos, mas podem ter - e acreditamos que cada vez mais terão - um papel central na permanência e no sucesso acadêmico dos estudantes que hoje ingressam nas universidades federais.

De toda forma, é preciso pensar em ações inovadoras que levem em consideração os percursos do público cada vez mais diversificado das universidades públicas e suas experiências cotidianas, consolidando políticas mais participativas, construídas coletivamente e pensadas a partir de seus sujeitos e não como mera estratégia de governança.

Esperamos que as informações e reflexões aqui apresentadas instiguem novas análises sobre as ações necessárias, imprescindíveis e mais eficazes para garantir o sucesso acadêmico dos estudantes na educação superior. 


\section{Referências}

Almeida, W. M. (2012). Ampliação do Acesso ao Ensino Superior Privado Lucrativo Brasileiro: Um Estudo Sociológico com Bolsistas do Prouni na Cidade de São Paulo. (Tese de doutorado). Programa de Pós-Graduação em Sociologia da Universidade de São Paulo. São Paulo: USP.

Baker, D. P. (2014). The schooled society: The educational transformation of global culture. Stanford, CA: Stanford University Press.

Bourdieu, P. \& Champagne, P. (1992). Os excluídos do interior. In: Nogueira, M. A.; Catani, A. (Orgs.). Escritos de Educação (11 ed, pp. 217-227). Petrópolis: Vozes, 2010.

BRASIL (2010). PNAES. Plano Nacional de Assistência Estudantil. Decreto No. 7.234/2010. Recuperado em: http:// www.planalto.gov.br/ccivil_03/_Ato2007-2010/2010/Decreto/D7234.htm.

BRASIL (2014). Plano Nacional de Educação 2014-2024 (Lei 13.005/2014). Recuperado em: http://www.planalto.gov. br/ccivil_03/_Ato2011-2014/2014/Lei/L13005.htm.

BRASIL (2010). Decreto $N^{o} 7.234$, de 19 de julho de 2010. Dispões sobre o Programa Nacional de Assistência Estudantil - PNAES.

Coulon, A. (2008). A condição de estudante: A entrada na vida universitária. Salvador: Edufba.

Daflon, V., Campos, L. A., Feres Junior, J. (2014). Ações afirmativas raciais no ensino superior público brasileiro: Um panorama analítico. Cadernos de Pesquisa (v.43, n.148, pp. 302-327), 2013, jan-abril.

Heringer, R. (2001). Mapeamento de ações e discursos de combate às desigualdades raciais no Brasil. Estudos AfroAsiáticos (UCAM. Impresso), Rio de Janeiro, v. 23, n.2, p. 291-334.

Heringer, R. (2002a). Desigualdades raciais no Brasil: sintese de indicadores e desafios no campo das políticas públicas. Cadernos de Saúde Pública (v.18, p. 57-65).

Heringer, R. (2002b). The Challenge of Practice: Affirmative action and diversity programs in Brazil and the U.S. Brazil Project, Woodrow Wilson International Center for Scholars, Washington, DC.

Heringer, R. (2010). Ação afirmativa à brasileira: institucional idade, sucessos e limites da inclusão de estudantes negros no ensino superior no Brasil (2001-2008). In: Entre dados e fatos: Ação afirmativa nas universidades públicas brasileiras. Paiva, A. R. (org.). Rio de Janeiro: Editora PUCRio e Pallas, 2010, pp. 117-144.

Heringer, R. (2012). Dez anos de ação afirmativa: Mapas, balanços, aprendizados. In: Ações afirmativas e inclusão: Um balanço. Cadernos do GEA (n.2, jul./dez. 2012). Rio de Janeiro: FLACSO, GEA; UERJ, LPP, 2012.

Heringer, R. (2013a). Expectativas de acesso ao ensino superior: um estudo de caso na Cidade de Deus, Rio de Janeiro. 1. ed. Rio de Janeiro: Autor, 2013. v. 1. 48p.

Heringer, R. (2013b). O Próximo passo: as políticas de permanência na universidade pública. In: Paiva, A. R. (org.), Ação afirmativa em questão: Brasil, Estados Unidos, África do Sul e França. Rio de Janeiro: Ed. Pallas, pp. 74-99.

Heringer, R., Ferreira, R. (2009). Análise das principais políticas de inclusão de estudantes negros no ensino superior no Brasil no período 2001-2008. in Paula, M. de \& Heringer, R. (orgs.). Caminhos Convergentes: Estado e Sociedade na Superação das Desigualdades Raciais no Brasil. Rio de Janeiro: Fundação Heinrich Boll/ ActionAid, 2009.

Heringer, R. \& Honorato, G. (2014). Políticas de permanência e assistência no ensino superior público e o caso da Universidade Federal do Rio de Janeiro (UFRJ). In: Barbosa, M. Ligia O. (Org.). Ensino superior: Expansão e democratização. Rio de Janeiro: 7 Letras.

Heringer, R., Johnson, O. (Orgs.) (2015). Race, Politics and Education in Brazil: Affirmative action in higher education. 1. ed. New York: Palgrave Macmillan, v. 1. 260p.

Heringer, R., Klitzke, M. (2017). O ENEM/SISU e as ações afirmativas em cursos de prestígio da UFRJ. In: Santos, G. G. dos; Vasconcelos, L.; Sampaio, S. M. R. (Org.). Observatório da Vida Estudantil: Dez anos de estudos sobre vida e cultura universitária - percurso e novas perspectivas. Salvador: EdUFBA, v. 1, p. 37-58.

Heringer, R., Sampaio, S. M. R., Santos, G. G. (2016). Access to higher education and inequality in Brazil. In: Saeed Paivandi; K.M.Joshi. (Org.). Equity in Higher Education: A Global Perspective. Delhi: Studera Press, 2016, v. 1, p. $35-53$.

Honorato, G., Vargas, H. M.; Heringer, R. (2014). Assistência estudantil e permanência na universidade pública: Refletindo sobre os casos da UFRJ e UFF. In: $38^{\circ}$ Encontro Anual da ANPOCS, 2014, Caxambu - MG. Anais do 38o Encontro Anual da ANPOCS.

Honorato, G. (Org.); Heringer, R. (Org.) (2015). Acesso e Sucesso no Ensino Superior: Uma Sociologia dos Estudantes. Rio de Janeiro: 7 Letras, v. 1. 238p.

INEP/MEC (2018). Censo da Educação Superior 2017. Divulgação dos principais resultados. Brasília: MEC.

IPEA (INSTITUTO DE PESQUISA ECONÔMICA APLICADA) (2008). PNAD 2007: Primeiras Análises. Brasília: IPEA, Comunicado da Presidência No. 12. 
Jodas, J. e Kawagami, E. (2011). Políticas de acesso ao ensino superior: Os desdobramentos na configuração dos programas de ação afirmativa no Brasil. Trabalho apresentado no XI Congresso Luso-Afro-Brasileiro de Ciências Sociais. Salvador: UFBA.

Martins, M. K. (2018). Há tendência de democratização no acesso a cursos de prestígio da UFRJ? Análise com base no perfil dos ingressantes - 2013 a 2016. (Dissertação de Mestrado). Programa de Pós-Graduação em Educação, UFRJ.

Menezes Filho, N. A.; Oliveira, A. P. (2014). Contribuição da Educação para a Queda na Desigualdade de Renda per Capita no Brasil. São Paulo: Centro de políticas Públicas do INSPER, Policy Papers. n. 9, pp.1-29.

Menezes, S. C. (2012). Assistência estudantil na educação superior pública: O programa de bolsas implementado pela Universidade Federal do Rio de Janeiro. (Dissertação de mestrado). Programa de Pós-Graduação em Serviço Social). Rio de Janeiro: PUC-Rio.

Neves, C. E. B. (2012). Ensino superior no Brasil: Expansão, diversificação e inclusão. Congresso da LASA. São Francisco (EUA), 23 a 26 de maio de 2012.

Neves, C. E. B., Sampaio, H., Heringer, R. (2018). A institucionalização da pesquisa sobre ensino superior no Brasil. Revista Brasileira de Sociologia, v. 6, p. 19-41, 2018.

Nunes, E., Martignoni, E. e Carvalho, M. M. (2003). Expansão do Ensino Superior: Restrições, Impossibilidades e Desafios Regionais. Rio de Janeiro: DATABRASIL/UCAM/ Observatório Universitário. Documento de Trabalho $\mathrm{N}^{\mathrm{o}} .25$.

Paixão, M., Rossetto, I., Montovanele, Fabiana, Carvano, L. M. (2011). Relatório Anual das Desigualdades Raciais no Brasil: 2009-2010. Rio de Janeiro: Garamond.

Prates, A. A., \& Collares, A. C. M. (2014). Desigualdade e expansão do ensino superior na sociedade contemporânea. Belo Horizonte: Fino Traço.

Ristoff, D. (2013). Perfil socioeconômico do estudante de graduação uma análise de dois ciclos completos do ENADE (2004 a 2009). Cadernos do GEA, Rio de Janeiro, n. 4, jul./dez.

Santos, C. T. (2011). A chegada ao ensino superior: o caso dos bolsistas do PROUNI na PUC-Rio. (dissertação de mestrado). Programa de Pós-Graduação em Sociologia e Antropologia/ IFCS/UFRJ, Rio de Janeiro.

Santos, G.; Machado, C. de O. X.; Brito, L. M. de (2012). Itinerários de Jovens Universitários no Recôncavo da Bahia. II Colóquio Internacional do Observatório da Vida Estudantil: Universidade, responsabilidade social e juventude. 31 de maio, 01 e 02 de junho de 2012. UFRB - Campus Cachoeira, Centro de Artes, Humanidades e Letras, prédio da Fundação Hansen.

Santos, R. E. dos (2003). Racialidade e novas formas de ação social: o pré-vestibular para negros e carentes. In: Santos, R. E \& Lobato, F. (orgs.), Ações afirmativas: políticas públicas contra as desigualdades raciais. Rio de Janeiro: DP\&A, 2003, pags. 127-153.

Sousa, L. P. e Portes, E. A. (2011). As propostas de políticas/ações afirmativas das universidades públicas e as políticas/ ações de permanência nos ordenamentos legais. Revista Brasileira de Estudos Pedagógicos. Brasília, v. 92, n. 232, p. 516-541, set./dez. 2011.

Vargas, H. M. (2012). Políticas de permanência na Universidade Federal Fluminense: um estudo na perspectiva das carreiras e da interiorização. In: Maria de Fátima Costa de Paula; Maria das Graças Martins da Silva. (Org.). As políticas de democratização da educação superior nos estados do Rio de Janeiro e de Mato Grosso. 1ed. Cuiabá: EduUFMT.

Vargas, H. M., Heringer, R. R. (2016). Políticas de Permanência e assistência estudantil nas universidades federais brasileiras: uma análise a partir dos websites. In: Gerson Tavares do Carmo. (Org.). Sentidos da permanência na educação: O anúncio de uma construção coletiva. Rio de Janeiro: Tempo Brasileiro, v. 1, p. 175-198.

Vargas, H. M., Heringer, R. (2017). Políticas de permanência no ensino superior público em perspectiva comparada: Argentina, Brasil e Chile. Archivos analíticos de políticas educativas / Education policy analysis archives (25, p. 72-108).

Recebido 27/09/2018

Reformulado 19/10/2018

Aceite Final 22/10/2018

Sobre a autora

Rosana Heringer é Doutora em Sociologia (IUPERJ), Vice-Diretora da Faculdade de Educação da UFRJ (20162019), professora e pesquisadora do Programa de Pós-Graduação em Educação e dos cursos de graduação da Faculdade de Educação da Universidade Federal do Rio de Janeiro (FE/UFRJ). Coordenadora do LEPES - Laboratório de Estudos e Pesquisas em Educação Superior, da Faculdade de Educação da UFRJ. 